\title{
Fiber Metal Laminatların Şekillendirilebilme Kabiliyetinin İncelenmesi
}

\author{
Ali IŞIKTAŞ*1®, Vedat TAŞKIN2® \\ 1Tekirdağ Namık Kemal Üniversitesi, Hayrabolu Meslek Yüksekokulu, Makine Bölümü, 59400, Tekirdağ, Türkiye \\ 2Trakya Üniversitesi, Mühendislik Fakültesi, Makina Mühendisliği Bölümü, 22100, Edirne, Türkiye
}

(Alınış / Received: 13.02.2020, Kabul / Accepted: 09.09.2020, Online Yayınlanma / Published Online: 20.12.2020)

Anahtar Kelimeler Şekillendirilebilirlik, Fiber metal laminat, Bükme kuvveti, Karbon elyaf
Özet: Bu çalışmada, havacılık sektöründe kullanılan fiber metal laminatların (FML) şekillendirilebilme kabiliyeti deneysel olarak incelenmiștir. FML numunelerin alt ve üst tabakalarında iki farklı kalınlıkta $(0,6$ ve 1,2 mm) Al5754-H22 sac levhalar kullanılmıștır. FML numunelerin orta tabakasında prepreg karbon elyaf kumaștan üretilen karbon elyaf plaka bulunmaktadır. FML malzemelerin șekillendirilme kabiliyetini incelemek amacıyla numuneler farklı bükme açllarında şekillendirilmiştir. Deneyler sırasında 0,6 mm Al 5754 kullanılan FML numuneler tüm bükme açılarında şekillendirilirken, 1,2 mm Al 5754 kullanılan FML numunelerin $75^{\circ}$ ve $90^{\circ}$ bükme testlerinde ise numunelerin dış tarafındaki alüminyum tabakasında yırtılma hasarı görülmüştür. Ayrıca FML numunelerin şekillendirilmesinde, bükme açısı ve alüminyum tabaka kalınlığının artmasıyla bükme kuvveti değerinin arttığı tespit edilmiştir.

\section{Investigation on Formability of Fiber Metal Laminates}

\section{Keywords}

Formability,

Fiber metal laminate,

Bending force,

Carbon fiber

\begin{abstract}
In this study, the formability of fiber metal laminates (FML) used in aerospace industry were experimentally examined. Al5754-H22 sheets in two different thicknesses $(0.6$ and $1.2 \mathrm{~mm}$ ) were used in top and bottom layers of FML specimens. Carbon fiber plates made of prepreg carbon fiber fabrics were placed in the middle layer of FML specimens. In order to examine the formability of FML materials, the specimens were formed in different bending angles. While all FML specimens with $0.6 \mathrm{~mm} \mathrm{Al} 5754$ were formed in all bending angles throughout the experiments, crack failures were observed in outer aluminum layer of the FML specimens with $1.2 \mathrm{~mm} \mathrm{Al} 5754$ at $75^{\circ}$ and $90^{\circ}$ bending angles. It was also reported in forming of FML specimens that the bending force value increased as the bending angle and the thickness of aluminum layer increased.
\end{abstract}

\section{Giriş}

Havacılık ve otomotiv endüstrisinde önemli avantajlar sunan fiber metal laminatların (FML) kullanımına ve imalatına artan bir ilgi bulunmaktadır [1]. Özellikle, havacılı sektöründe yüksek performanslı ve hafif yapılara olan talep nedeniyle fiber metal laminatların (FML) önemi artmıştır [2]. FML'ler metal malzemelerin yorulma ve hasar toleransını iyileștirmek amacıyla ince metal malzemeler ile fiber malzemelerin birleştirilmesiyle oluşturulan hibrit malzemelerdir [3]. Metal ve fiber malzemelerin çeşitli kombinasyonlarla bir araya gelmesiyle oluşan fiber metal laminatlar geleneksel malzemelere göre üstünlük sağlamaktadır [4]. FML'lerin aynı kalınlıktaki yekpare alüminyum malzemeye göre yoğunluğu daha azdır [5]. Örneğin karbon elyaf-alüminyumdan oluşan hibrit bir malzeme eşdeğer alüminyum malzemeye göre \%56'ya kadar ağırlık tasarrufu sağlamaktadır [6,7]. $\mathrm{Bu}$ avantaj havacılık sektörü gibi ağırlığın önemli olduğu bir alanda daha fazla önem arz etmektedir. Ayrıca, FML'ler korozyon direnci ve nem direnci gibi çevresel etkilere karşı yekpare alüminyum malzemeye göre daha dayanıklıdır [8].

FML'lerin üretimi esnasında birçok şekillendirme ve kürleme aşamalarına gereksinim duyulmaktadır. Özellikle, karmaşık geometriye sahip FML'lerin üretilmesinde bu aşamalar yoğun işgücü ve pahalı işlemlere sebebiyet verdiği için maliyet artışına neden olmaktadır. $\mathrm{Bu}$ sebeple FML'lerin üretimi esnasında alternatif bir şekillendirme yöntemine ihtiyaç duyulmaktadır [4]. $\mathrm{Bu}$ nedenle, FML malzemeler bu çalışmada sac metal şekillendirme prosesinde şekillendirilmiştir. 
FML'lerin şekillendirilebilme kabiliyeti düşük olduğu için bükme işlemi esnasında malzemede çeşitli geometrik kusurlar meydana gelmektedir [2]. Yapılan deneysel çalışmalar incelendiğinde, FML'lerin şekillendirilmesi esnasında malzemelerde yırtılma, çatlama, deformasyon ve birleşme bölgesinden ayrılmalar görülmüştür [9-13].

Hahn ve arkadaşları, farklı fiber yönlerindeki FML malzemelerin farklı bükme sıcaklıklarında şekillendirilmesi üzerine deneysel bir çalışma gerçekleştirmiştir. Düşük sıcaklıktaki bükme testlerinde, malzemelerin büküm bölgesi üzerinde yırtılma hasarı oluştuğunu belirtmişlerdir [14]. Uriya ve arkadaşları, fiber metal laminatların ve karbon elyaf plakaların farklı sıcaklıklarda şekillendirilmesini incelemişlerdir. Deneylerde, sıcaklığın artmasıyla fiber metal laminatların bükülebilme kabiliyetinin arttığını belirtmișlerdir. Ayrica, sadece karbon fiberden oluşan deney numunelerinin bükülmesinde ise numune yüzeyinde yırtılma hasarının olduğu belirtilmiştir [15].

Fiber metal laminatların şekillendirilebilme kabiliyeti üzerine çalışmalar literatürde yer aldığı görülmüş, fakat farklı bükme açllarındaki davranıșı henüz çalışılmamış olduğu belirlenmiştir. $\mathrm{Bu}$ sebeple çalışmada, fiber metal laminatların farklı bükme açılarında şekillendirilebilme kabiliyeti araștırılmıștır.

\section{Materyal ve Metot}

FML numunelerin alt ve üst tabakalarında iki farklı kalınlıkta $(0,6$ ve $1,2 \mathrm{~mm})$ Al5754-H22 sac levhalar kullanılmıştır. FML numunelerin orta tabakasında ise 0,15 mm kalınlığında karbon elyaf plaka bulunmaktadır. Karbon elyaf plakanın üretiminde tek yönlü prepreg karbon elyaf kumaşlar kullanılmıştır. FML numuneyi oluşturan alüminyum sac, karbon elyaf plaka ve yapıştırıcının dizilimi Şekil 1'de gösterilmiştir. Karbon elyaf kumaşın özellikleri Tablo 1'de, Al5754-H22'nin mekanik özellikleri Tablo 2'de verilmiştir.

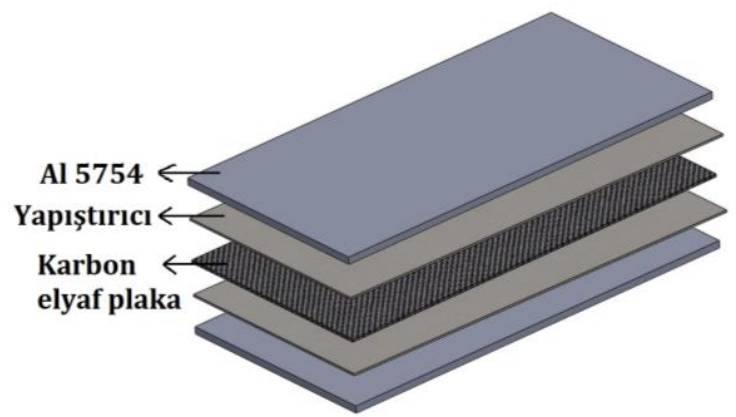

Şekil 1. FML yapının oluşum şeması.

Tablo 1. Karbon elyaf kumașın özellikleri

\begin{tabular}{ccccc}
$\begin{array}{c}\text { Dokuma } \\
\text { türü }\end{array}$ & $\begin{array}{c}\text { Elyaf } \\
\text { ağırlığı } \\
\left(\mathrm{gr} / \mathrm{m}^{2}\right)\end{array}$ & $\begin{array}{c}\text { Reçine } \\
\text { ağırlığı } \\
\left(\mathrm{gr} / \mathrm{m}^{2}\right)\end{array}$ & $\begin{array}{c}\text { Reçine } \\
\text { oranı } \\
(\%)\end{array}$ & $\begin{array}{c}\text { Elyaf } \\
\text { kalınlığı } \\
(\mathrm{mm})\end{array}$ \\
\hline
\end{tabular}

\begin{tabular}{lllll} 
Plain & 93 & 107 & $35-37$ & 0,15 \\
\hline
\end{tabular}

Tablo 2. Alüminyum 5754-H22 kimyasal bileșimi (\%)

\begin{tabular}{cccccccc}
\hline $\mathbf{S i}$ & $\mathbf{F e}$ & $\mathbf{C u}$ & $\mathbf{M n}$ & $\mathbf{M g}$ & $\mathbf{Z n}$ & $\mathbf{T i}$ & $\mathbf{C r}$ \\
\hline 0,40 & 0,40 & 0,10 & 0,50 & 3,2 & 0,20 & 0,15 & 0,30
\end{tabular}

Alüminyum ve karbon elyaf plakalar arasında daha iyi bir yapışma dayanımı elde etmek için mikroskobik yapışma alanını arttıran pürüzlendirme işlemi yapılmıştır [16]. Zımpara ile aşındırma işlemi esnasında yüzeylerde biriken alüminyum ve karbon elyaf tozlarını temizlemek için LPS marka Hdx temizleyici kullanılmıştır. $\mathrm{Bu}$ yüzey temizleyici solvent, zımparalama ișleminde olușan talaș, kir ve tozların yapıștırma yüzeyindeki gözenekleri doldurmasını engellemektedir [17].

Yapıştırma işlemi öncesi Devcon marka Metal Prep 90 primer kullanılmıștır. Metal Prep 90 alüminyum ve paslanmaz çelik yüzeylerde metakrilat bazlı yapıștırıcıların daha uzun süreli ve daha kalıcı yapışmasını sağlayan kimyasal bir primer ve yüzey düzenleyicidir [18]. Deneylerde bu primer, yapıştırılacak malzeme yüzeylerine ince bir katman halinde yüzeyi kaplayıncaya kadar püskürtülerek uygulanmıştır. Kullanılan primer oda sıcaklığında hızlı kuruma yaptığı için 3 dakika bekledikten sonra hemen yapıştırma işlemine geçilmiştir. Primer uygulanmış alüminyum levha yüzeyleri Şekil 2'de gösterilmiştir.

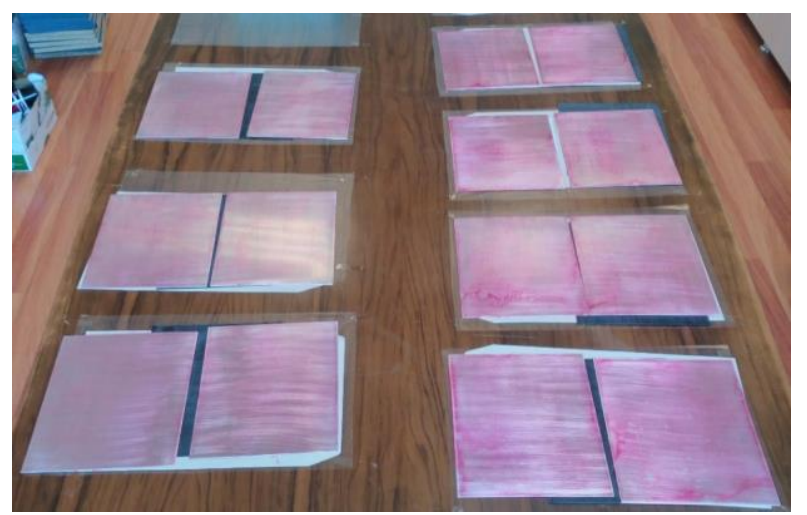

Şekil 2. Primer uygulanmış alüminyum levha yüzeyleri.

Alüminyum ve karbon elyafın yapıştırma işleminde, Devcon marka Plastic Welder yapıştırıcı kullanılmıştır. İki bileșenli olan yapıștırıcı ilk önce bir kaba boşaltılmış ve burada homojen bir karışım elde edilene kadar karıştırılmıştır. Daha sonra, karıştırılan yapıştırıcı birleştirilecek parçaların yüzeylerine düzgün bir biçimde sürülmüştür. Yapıştırıcının oda sıcaklığında iyi bir yapıştırma mukavemetine sahip bir tabaka oluşturabilmesi için yapıştırılan malzemeler yapıştırma aparatı içinde 24 saat sabit basınç altında bekletilmiştir.

Yapıştırma işlemi sonrası 200x250 mm boyutlarındaki FML plakalar su jeti ile alüminyum sacın haddeleme yönünde, 30×60 mm ebatlarında kesilerek deney numuneleri oluşturulmuştur. Su jeti 
kullanıldığı için kesilen deney numunelerinin kenarlarında herhangi bir çapak meydana gelmemiştir. FML plakaların su jeti ile kesimi Şekil 3'de gösterilmiştir.

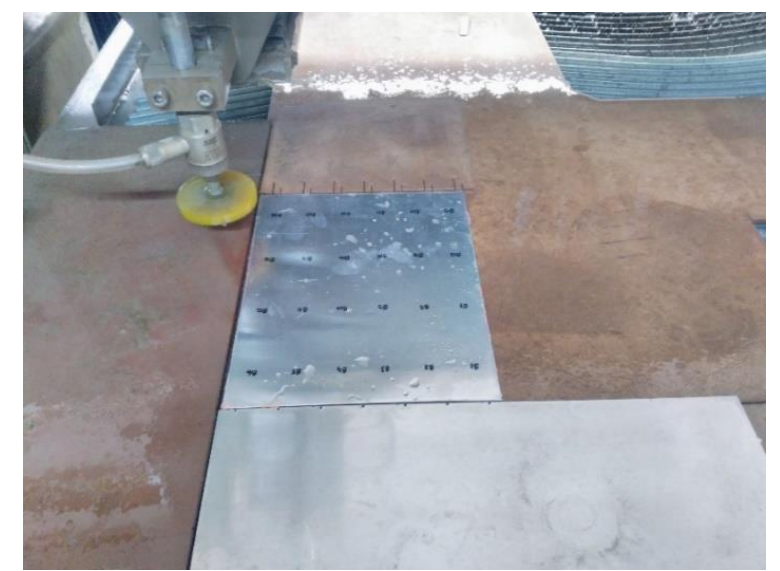

Şekil 3. FML plakaların su jeti ile kesimi.

Su jeti ile kesme işlemi sonrası bükme deneylerinde kullanılan FML deney numuneleri Şekil 4'de gösterilmiştir.

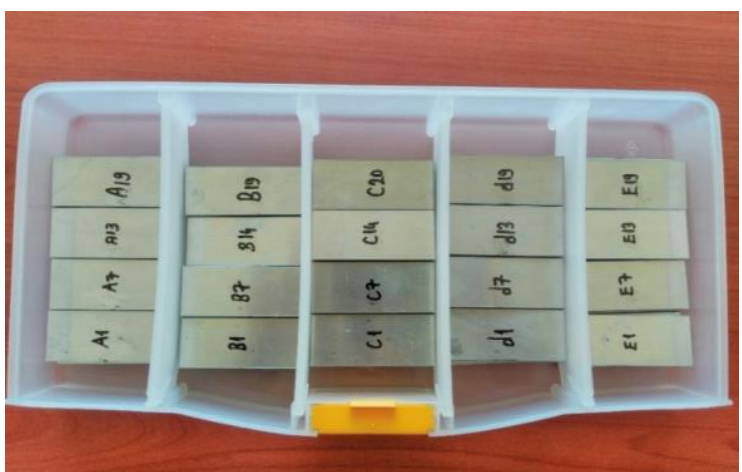

Şekil 4. FML deney numuneleri.

FML malzemelerin şekillendirilebilme kabiliyetini incelemek amacıyla numuneler farklı bükme açılarında şekillendirilmiştir. Deneylerde, FML numuneleri şekillendirmek için $15^{\circ}, 30^{\circ}, 45^{\circ}, 60^{\circ}, 75^{\circ}$ ve $90^{\circ}$ bükme açlarında $\mathrm{V}$ bükme kalıpları kullanılmıştır. Yapılan deneylerde bükme hızı ve zımba yarıçapı sabit alınmıştır.

\section{Bulgular}

\subsection{Bükme Açısının FML Malzemenin Şekillendirilmesi Üzerindeki Etkisi}

FML numunelerin orta tabakasında $0,15 \mathrm{~mm}$ kalınlığında karbon elyaf plakalar kullanılırken, alt ve üst tabakalarında ise iki farklı kalınlıkta $(0,6$ ve 1,2 mm) Al5754 sac kullanılmıştır. Üretilen FML numuneler $15^{\circ}, 30^{\circ}, 45^{\circ}, 60^{\circ}, 75^{\circ}$ ve $90^{\circ}$ bükme açılarında șekillendirilmiștir. Bükme ișlemi sonrası FML malzemelerin yapısı ve bükme kuvvetleri incelenmiştir.
0,6 mm Al5754 ve 0,15 mm kalınlığında karbon elyaf plakadan üretilen FML numunelerin bükme işlemi sonrası görünümleri Şekil 5'de verilmiștir.

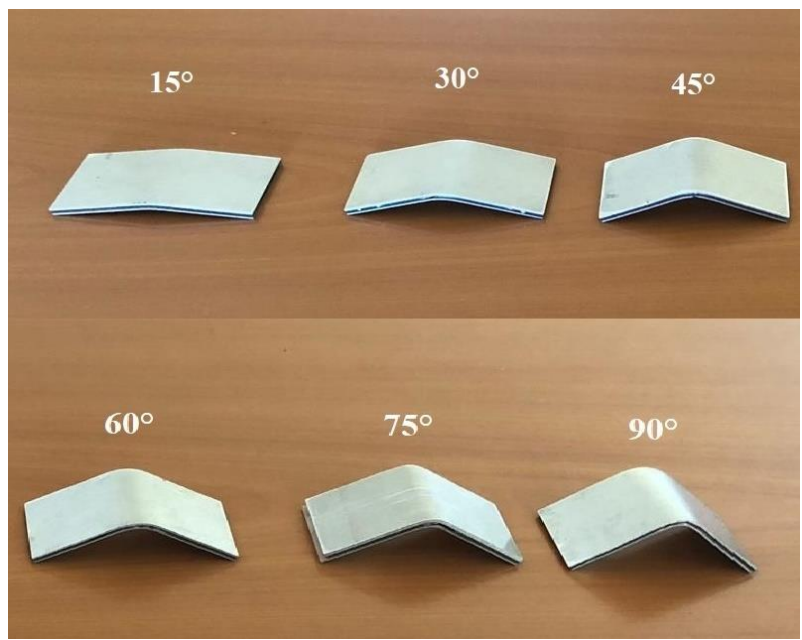

Şekil 5. 0,6 mm Al 5754 ve 0,15 mm karbon elyaf plakadan üretilen FML numunelerin bükme sonrası görünümleri.

1,2 mm Al5754 ve $0,15 \mathrm{~mm}$ kalınlığında karbon elyaf plakadan üretilen FML numunelerin bükme işlemi sonrası görünümleri Şekil 6'da verilmiştir.

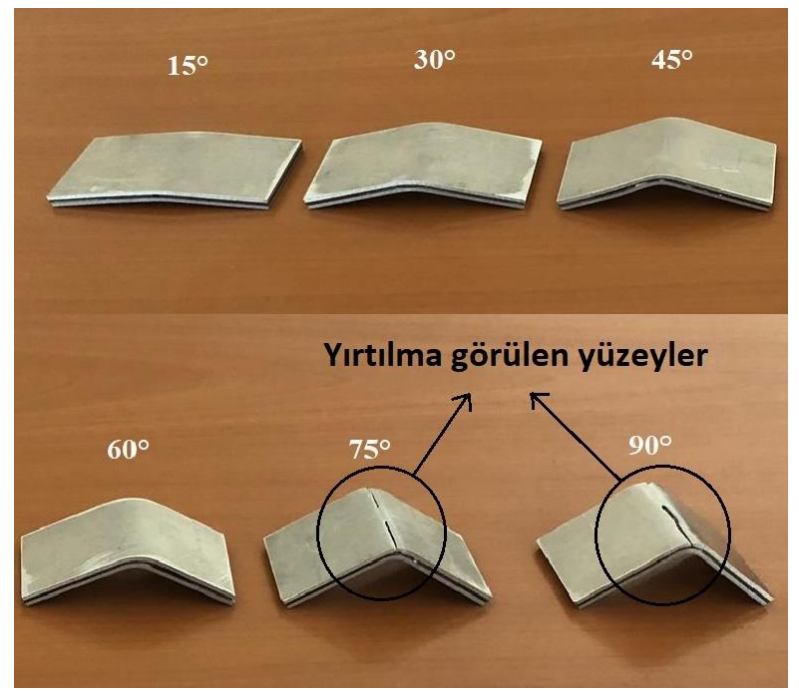

Şekil 6. 1,2 mm Al 5754 ve 0,15 mm karbon elyaf plakadan üretilen FML numunelerin bükme sonrası görünümleri.

Bükme işlemi sonunda $15^{\circ}, 30^{\circ}, 45^{\circ}, 60^{\circ}$ bükme açlarındaki numunelerde yırtılma hasarı görülmezken, $75^{\circ}$ ve $90^{\circ}$ bükülen numunelerin dış yüzeyindeki alüminyumlarda yırtılma hasarı oluşmuştur. $75^{\circ}$ ve $90^{\circ}$ bükülen numunelerde oluşan yırtılma hasarları Şekil 6'da gösterilmiştir. FML numunelerin şekillendirilmesinde, bükme açısının artması ile yırtılma hasarlarının oluştuğu tespit edilmiştir. Bükme açısının artması, numunenin büküm bölgesinde oluşan gerilmeleri arttırmaktadır. Karbon elyaf ve alüminyum tabakaları kaymayacak şekilde bağlandığından, bu bükülme açlarında gelişen büyük arayüzey kesme gerilmeleri nedeniyle yırtılma hasarlarının meydana geldiği sonucuna varılabilir. Fiber metal laminatların şekillendirilmesi 
neticesinde malzemenin diş yüzeyinde oluşan yırtılma hasarı benzer çalışmalarda da görülmüştür $[19,20]$.

\subsection{Bükme Açısı ve Alüminyum Kalınlığının Bükme Kuvveti Üzerindeki Etkisi}

Deneylerin yapıldığı bükme cihazından alınan verilere göre, FML deney numunelerin şekillendirilmesi ait bükme kuvveti-zımba strok eğrileri olușturulmuștur. Farklı kalınlıkta Al5754 kullanılan FML numunelerin farklı bükme açılarında şekillendirilmesine ait bükme kuvveti-zımba strok eğrileri Şekil 7-12'de gösterilmiștir.

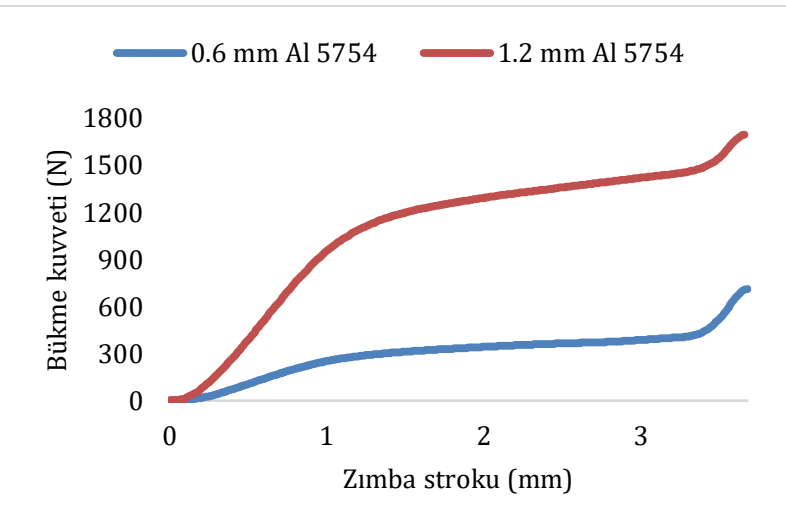

Şekil 7. Farklı kalınlıkta Al5754 kullanılan FML numunelerin $15^{\circ}$ bükme açısındaki bükme kuvvetleri.

Şekil 7 incelendiğinde, $15^{\circ}$ lik bükme işleminde 0,6 mm Al5754 kullanilan FML numunelerde ortalama bükme kuvveti $708 \mathrm{~N}$ iken 1,2 mm Al5754 kullanılan FML numunelerde ise $1692 \mathrm{~N}$ olarak ölçülmüştür.

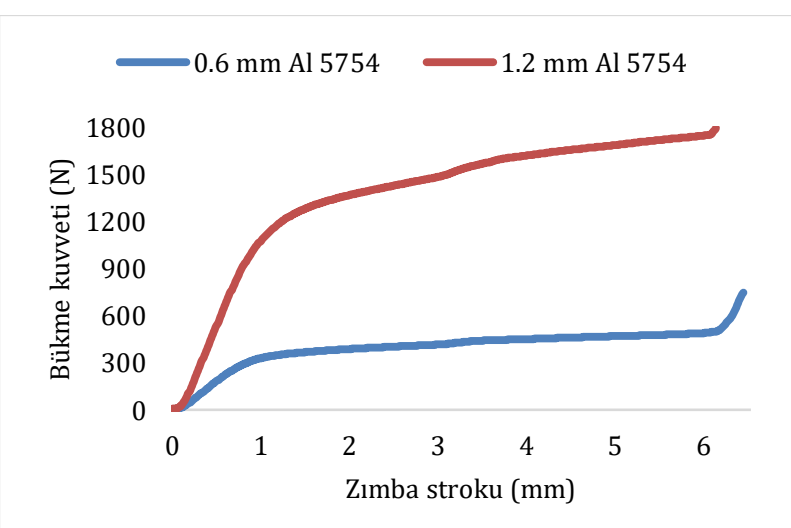

Şekil 8. Farklı kalınlıkta Al5754 kullanılan FML numunelerin $30^{\circ}$ bükme açısın daki bükme kuvvetleri.

Şekil 8 incelendiğinde, $30^{\circ}$ lik bükme işleminde 0,6 mm Al5754 kullanılan FML numunelerde ortalama bükme kuvveti $747 \mathrm{~N}$ iken, 1,2 mm Al5754 kullanılan FML numunelerde ise 1787 N olarak ölçülmüştür.

Şekil 9 incelendiğinde, $45^{\circ}$ lik bükme işleminde 0,6 mm Al5754 kullanılan FML numunelerde ortalama bükme kuvveti $904 \mathrm{~N}$ iken 1,2 mm Al5754 kullanılan FML numunelerde ise 2066 N olarak ölçülmüştür.

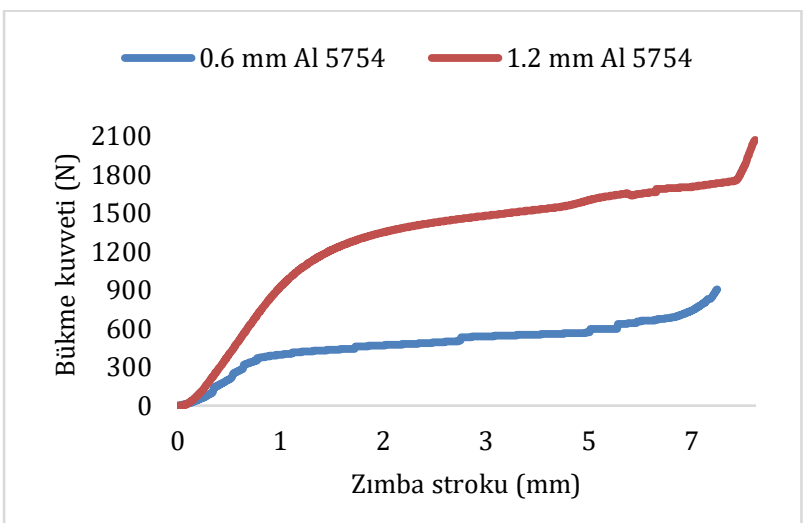

Şekil 9. Farklı kalınlıkta Al5754 kullanılan FML numunelerin $45^{\circ}$ bükme açısındaki bükme kuvvetleri.

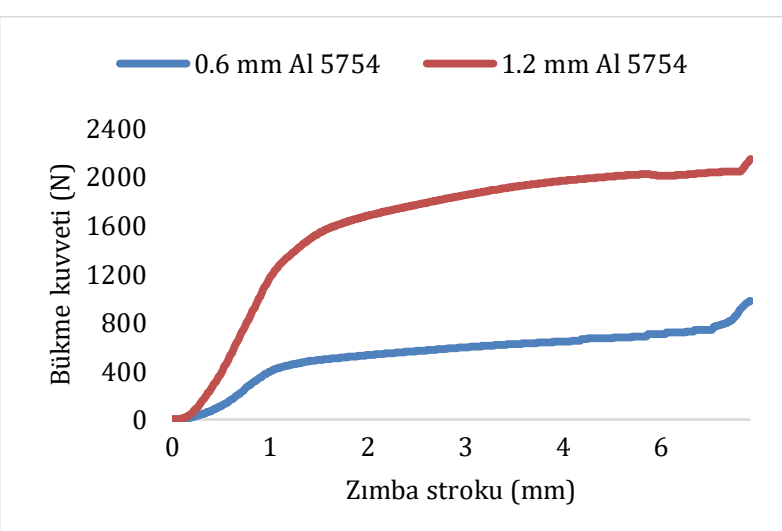

Şekil 10. Farklı kalınlıkta Al5754 kullanılan FML numunelerin $60^{\circ}$ bükme açısındaki bükme kuvvetleri.

Șekil 10 incelendiğinde, $60^{\circ}$ lik bükme işleminde 0,6 mm Al5754 kullanılan FML numunelerde ortalama bükme kuvveti $976 \mathrm{~N}$ iken, 1,2 mm Al5754 kullanılan FML numunelerde ise $2186 \mathrm{~N}$ olarak ölçülmüştür.

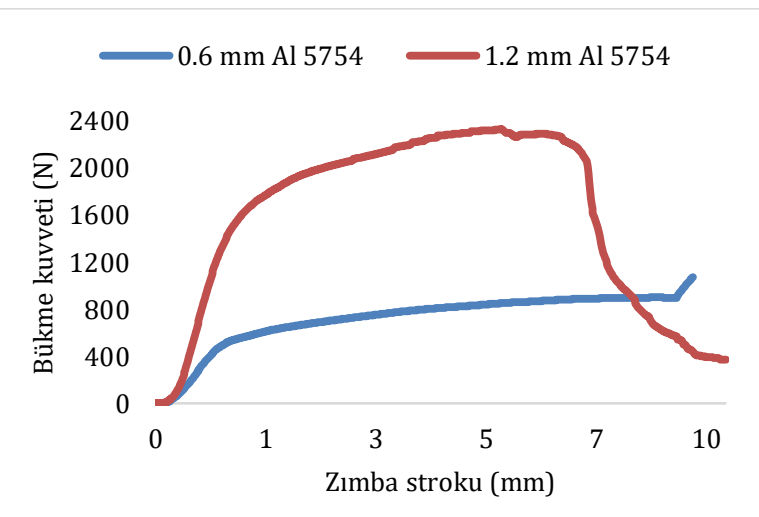

Sekil 11. Farklı kalınlıkta Al5754 kullanılan FML numunelerin $75^{\circ}$ bükme açısındaki bükme kuvvetleri.

Şekil 11 incelendiğinde, $75^{\circ}$ lik bükme işleminde 0,6 mm Al5754 kullanılan FML numunelerde ortalama bükme kuvveti $1068 \mathrm{~N}$ iken 1,2 mm Al5754 kullanılan FML numunelerde ise malzemenin dış yüzeyindeki alüminyumda yırtılma hasarı meydana geldiği için bükme kuvvetinde 2326 N'dan sonra azalma görülmüștür. 


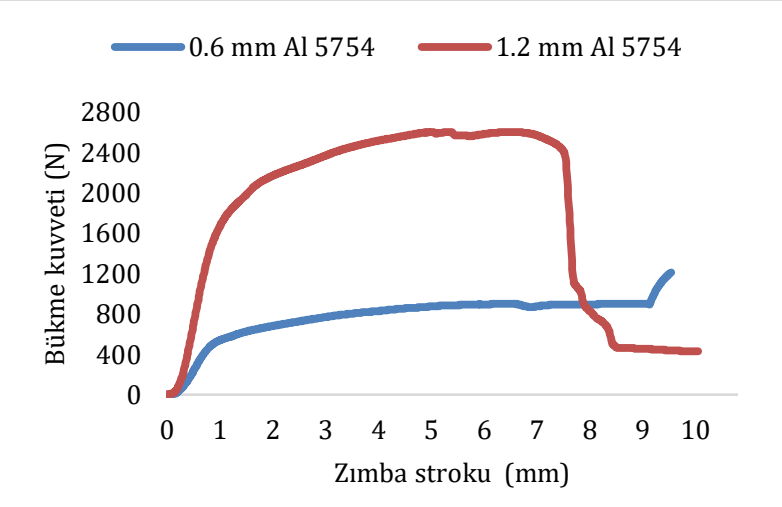

Şekil 12. Farklı kalınlıkta Al5754 kullanılan FML numunelerin $90^{\circ}$ bükme açısındaki bükme kuvvetleri

Şekil 12 incelendiğinde, $90^{\circ}$ lik bükme işleminde 0,6 mm Al5754 kullanilan FML numunelerde ortalama bükme kuvveti $1206 \mathrm{~N}$ iken $1,2 \mathrm{~mm}$ Al5754 kullanılan FML numunelerde ise malzemenin dış yüzeyindeki alüminyumda yırtılma hasarı meydana geldiği için bükme kuvvetinde 2602 N'dan sonra azalma görülmüştür.

\section{Tartışma ve Sonuç}

Bu çalışmada karbon elyaf plaka ve alüminyum sac levhadan üretilen fiber metal laminatların şekillendirilme kabiliyeti incelenmiştir. Ayrıca, FML malzemelerin şekillendirilmesinde bükme kuvvetizımba strok eğrileri analiz edilmiștir.

Farklı kalınlıkta $(0,6$ ve $1,2 \mathrm{~mm})$ Al5754 kullanılan FML numunelerin farklı bükme açılarında $\left(15^{\circ}, 30^{\circ}\right.$, $45^{\circ}, 60^{\circ}, 75^{\circ}$ ve $90^{\circ}$ ) şekillendirilmesi esnasında, tüm bükme açlarında 1,2 mm Al5754 kullanılan FML numunelerde daha fazla bükme kuvveti gerektiği tespit edilmiştir.

0,6 mm Al5754 ve 0,15 mm kalınlığında karbon elyaf plakadan üretilen FML numunelerin farklı bükme açılarında şekillendirilmesi neticesinde, bükme açısının artması ile FML numunelerde (0,6/0,15/0,6 $\mathrm{mm}$ ) bükme kuvveti değerinin arttığı tespit edilmiştir.

1,2 mm Al5754 ve $0,15 \mathrm{~mm}$ kalınlı̆̆ında karbon elyaf plakadan üretilen FML numunelerin farklı bükme açılarında şekillendirilmesi neticesinde, bükme açısının artması ile FML numunelerde $(1,2 / 0,15 / 1,2$ $\mathrm{mm})$ bükme kuvveti değerinin arttığ tespit edilmiştir.

1,2 mm Al5754 ve $0,15 \mathrm{~mm}$ kalınlığında karbon elyaf plakadan üretilen FML numunelerin şekillendirilmesi neticesinde; $15^{\circ}, 30^{\circ}, 45^{\circ}, 60^{\circ}$ bükme açılarındaki numunelerde yırtılma hasarı görülmezken, $75^{\circ}$ ve $90^{\circ}$ bükülen numunelerin dış yüzeyindeki alüminyumlarda yırtılma hasarı oluşmuştur. Karbon elyaf plaka ve Al sac tabakaları kaymayacak șekilde bağlandığından, bu bükülme açılarında gelişen büyük arayüzey kesme gerilmeleri nedeniyle yırtılma hasarlarının meydana geldiği sonucuna varılabilir.

\section{Teşekkür}

Bu çalışma Trakya Üniversitesi Bilimsel Araştırma Projeleri Koordinasyon Birimince desteklenmiştir. Proje numarası: 2017/185.

\section{Etik Beyanı}

Bu çalışmada, "Yükseköğretim Kurumları Bilimsel Araştırma ve Yayın Etiği Yönergesi" kapsamında uyulması gerekli tüm kurallara uyulduğunu, bahsi geçen yönergenin "Bilimsel Araştırma ve Yayın Etiğine Aykırı Eylemler" başlı̆̆ı altında belirtilen eylemlerden hiçbirinin gerçekleștirilmediğini taahhüt ederiz.

\section{Kaynakça}

[1] Reyes, G., Kang, H. 2007. Mechanical Behavior of Lightweight Thermoplastic Fiber-Metal Laminates. Journal of Materials Processing Technology, 186(1-3), 284-290.

[2] Keipour, S., Gerdooei, M. 2019. Springback Behavior of Fiber Metal Laminates in HatShaped Draw Bending Process: Experimental and Numerical Evaluation. The International Journal of Advanced Manufacturing Technology, 100(5-8), 1755-1765.

[3] Şen, İ. 2015. Lay-up optimisation of fibre metal laminates: development of a design methodology for wing structures, Delft University of Technology, PhD Thesis, 61s, The Netherlands.

[4] Mosse, L., Compston, P., Cantwell, W. J., CardewHall, M., Kalyanasundaram, S. 2006. Stamp Forming of Polypropylene Based Fibre-Metal Laminates: The Effect of Process Variables on Formability. Journal of Materials Processing Technology, 172(2), 163-168.

[5] Gülcan, O., Tekkanat, K., Çetinkaya, B. 2019. Fiber Metal Laminatlar ve Uçak Sanayiinde Kullanımı Üzerine Bir İnceleme. Mühendis ve Makina, 60(697), 262-288.

[6] Kim, P. 1998. A Comparative Study of The Mechanical Performance and Cost of Metal, FRP, and Hybrid Beams. Applied Composite Materials, 5(3), 175-187.

[7] Huang, Z., Sugiyama, S., Yanagimoto, J. 2013. Hybrid Joining Process for Carbon Fiber Reinforced Thermosetting Plastic and Metallic Thin Sheets by Chemical Bonding and Plastic Deformation. Journal of Materials Processing Technology, 213(11), 1864-1874.

[8] Alderliesten, R. 2009. On The Development of Hybrid Material Concepts for Aircraft Structures. Recent Patents on Engineering, 3(1), 25-38. 
[9] Rajkumar, G. R., Krishna, M., Narasimhamurthy, H. N., Keshavamurthy, Y. C., Nataraj, J. R. 2014. Investigation of Tensile and Bending Behavior of Aluminum Based Hybrid Fiber Metal Laminates. Procedia Materials Science, 5, 60-68.

[10] Khalili, S. M. R., Daghigh, V., Eslami Farsani, R. 2011. Mechanical Behavior of Basalt FiberReinforced and Basalt Fiber Metal Laminate Composites under Tensile and Bending Loads. Journal of Reinforced Plastics and Composites, 30(8), 647-659.

[11] Wang, J., Yu, Y., Fu, C., Xiao, H., Wang, H., Zheng, X. 2020. Experimental Investigation of Clinching CFRP/Aluminum Alloy Sheet with Prepreg Sandwich Structure. Journal of Materials Processing Technology, 277, 116422.

[12] Botelho, E. C., Silva, R. A., Pardini, L. C., Rezende, M. C. 2006. A Review on The Development and Properties of Continuous Fiber/Epoxy/Aluminum Hybrid Composites for Aircraft Structures. Materials Research, 9(3), 247-256.

[13] Kim, S. Y., Choi, W. J., Park, S. Y. 2007. SpringBack Characteristics of Fiber Metal Laminate (GLARE) in Brake Forming Process. The International Journal of Advanced Manufacturing Technology, 32(5-6), 445-451.

[14] Hahn, M., Ben Khalifa, N., Weddeling, C., Shabaninejad, A. 2016. Springback Behavior of Carbon-Fiber-Reinforced Plastic Laminates with Metal Cover Layers in V-Die Bending. Journal of Manufacturing Science and Engineering, 138(12), 1-10.
[15] Uriya, Y., Ikeuch, K., Yanagimoto, J. 2014. Cold and Warm V-Bending Test for Carbon-FiberReinforced Plastic Sheet. Procedia Engineering, 81, 1633-1638.

[16] Urkmez Taskin, N., Taskin, V., Sahin, A. 2016. Kompozit Metal Köpük Malzemelerin Tek Bindirmeli Yapıștırma Bağlantılarının Kesme Dayanımının İncelenmesi. 4th International Conference on Welding Technologies and Exhibition, 11-13 Mayıs, Gaziantep, 1052-1059.

[17] Işıktaş, A., Taşkın, V. 2020. Alüminyum-Karbon Elyaf Sandviç Kompozit Levhaların V-Bükme İşleminde Bükme Açlarının ve Bükme Yönlerinin Geri Esneme Üzerindeki Etkisi. Balıkesir Üniversitesi Fen Bilimleri Enstitüsü Dergisi, 22(1), 281-290.

[18] Urkmez Taskin, N., Sahin, A. 2019. Effect of Aging Time at High Temperature on the Shear Strength of Adhesively Bonded Aluminum Composite Foam Joints. The Journal of Adhesion, 95(4), 308-324.

[19] Uriya, Y., Yanagimoto, J. 2016. Suitable Structure of Thermosetting CFRP Sheet for Cold/Warm Forming. International Journal of Material Forming, 9(2), 243-252.

[20] Yanagimoto, J., Ikeuchi, K. 2012. Sheet Forming Process of Carbon Fiber Reinforced Plastics for Lightweight Parts. CIRP annals, 61(1), 247-250. 